\title{
Slow Structural Change in India: Is It Related to Rising Relative Price of Agriculture? A Partial Equilibrium Model
}

\author{
Subhasankar Chattopadhyay \\ Department of Economics, Indian Institute of Management Indore, Indore, India \\ Email: subhasankarc@iimidr.ac.in
}

Received 25 April 2016; accepted 31 May 2016; published 3 June 2016

Copyright (C) 2016 by authors and Scientific Research Publishing Inc.

This work is licensed under the Creative Commons Attribution International License (CC BY).

http://creativecommons.org/licenses/by/4.0/

(c) (i) Open Access

\begin{abstract}
Economic growth across countries is associated with changes in the composition of sectoral output, employment and consumption structure, known as "structural change". With high growth rates in the Indian economy in the post liberalization period, structural change is expected to be rapid. However, the share of the manufacturing sector has "crossed" over that of the agriculture only very recently from the supply side and yet to cross over from the demand side. Through a simple partial equilibrium model, this paper shows that such slow structural change may be linked to a secular rise in the relative price of agricultural goods in India.
\end{abstract}

\section{Keywords}

Indian Economy, Relative Price Effect, Structural Change, Non-Homothetic Utility

\section{Introduction}

A well-documented feature of economic growth across economies is the associated changes in the composition of sectoral output, employment and consumption structure [1] known as "structural change". Such changes are observed across developing [2] and developed economies [3]-[6].

Two of the stylised facts of structural change are the following [7].

1) Falling expenditure share of goods (against services);

2) Falling relative price of goods compared to services.

These facts suggest that as per capita income rises, expenditure shares and relative price turn more towards income and price elastic goods.

Are the facts 1) and 2) mutually independent or related? Consider the case of India. The average growth rate 
in real GDP has been close to 6 percent in the post liberalization period. With such high growth rates, one expects structural change to be rapid. Chart 1 and Chart 2 show structural change (involving the manufacturing and agricultural sectors), from the supply and demand side respectively. The structural change seems to be slow; the share of manufacturing in the total output has just "crossed" over that of agricultural from the supply side and is yet to do so from the expenditure side. Similar observation has been noted by Binswanger-Mkhize [8].

This note argues that slow structural change is an outcome of the fact that India does not conform to the stylised fact 2). The argument involves use of some well-known properties of "non-homothetic" utility function.

\section{Structural Change in India}

All data are extracted from EPWRF [9] database. This database collects data from Central Statistical Office, Reserve Bank of India, Annual Survey of Industries in India and so on, and presents them in an easily accessible form. Chart 1 shows structural change from the supply side. The sectoral GDPs are at factor cost (2004-05 series) at constant prices. Chart 2 shows structural change from the demand side. To get an estimate of the expenditure shares, we have used private final consumption expenditure by object at constant prices (2004-05 series). For food consumption, the component "food" (the most significant part of agricultural goods) is taken from the head "food, beverages and tobacco" and for manufacturing consumption, we have added expenditures on 'clothing and footwear' to that on "furniture, furnishing and appliances". The total expenditure is computed as manufacturing plus food expenditure. Chart 2 shows that the "cross over" from food to manufacturing is yet to happen; food still occupies a large fraction of total expenditure in India. This note tries to uncover the underlying demand behaviour relating to observation of Chart 2 .

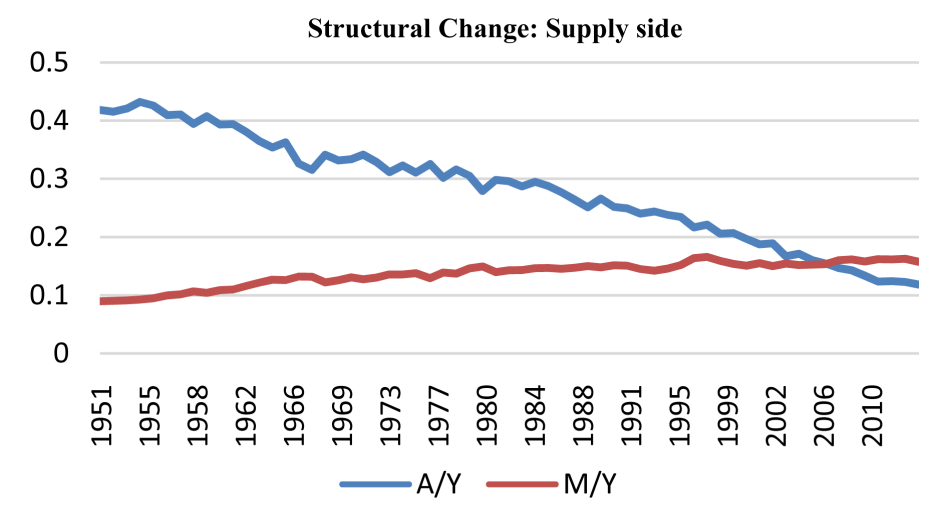

Chart 1. Behaviour of output shares of Agriculture (A) and Manufacturing (M) sectors in GDP (Y). Source: Author's calculation from EPWRF time series database.

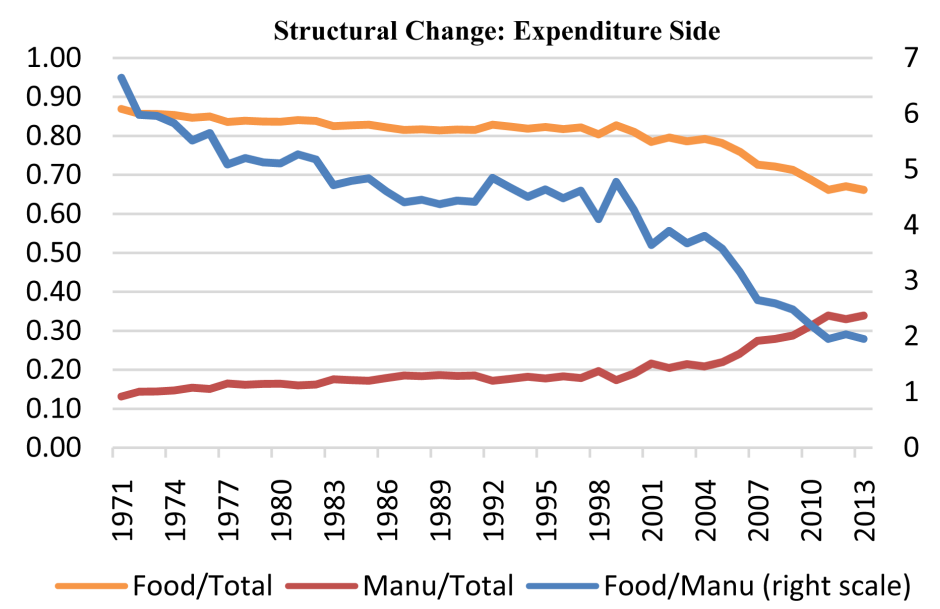

Chart 2. Behaviour of expenditures shares of food and manufacturing. Source: Author's calculation from EPWRF time series database. 


\section{Structural Change with Non-Homothetic Preference}

Non-homothetic utility function can neatly incorporate non-linear Engel curve and therefore is suitable for explaining structural change arising out of demand side imbalances. We use the simplest form here: the StoneGeary utility function.

The standard static utility maximization problem for a representative consumer is:

$$
\text { Max. } U(A, M)=\left(A-A_{0}\right)^{\alpha} M^{1-\alpha}
$$

Subject to the budget constraint:

$$
P_{A} A+P_{M} M=P Y
$$

where $A \& M$ : consumptions of agricultural (food) and manufacturing goods respectively, $A_{0}$ : subsistence consumption of "A"; $P_{A} \& P_{M}$ are respective absolute prices; $P$ : overall price level (an index of $P_{A} \& P_{M}$ ) and $Y$ : level of real GDP.

The subsistence expenditure is given by $P_{A} A_{0}$ (for $A<A_{0}$ utility is not defined). Rest $\left(Y-P_{A} A_{0}\right)$ is spent on "A" and "M" leading to the following demand functions.

$$
\begin{gathered}
D_{A}=A_{0}+\alpha\left(P Y-P_{A} A_{0}\right) / P_{A} \\
D_{M}=(1-\alpha)\left(P Y-P_{A} A_{0}\right) / P_{M}
\end{gathered}
$$

Note that, for $A_{0}=0$, demand functions reduce to standard Cobb-Douglas demand.

Let the expenditure shares of " $\mathrm{A}$ " and " $\mathrm{M}$ " be denoted by " $\theta$ " and " $1-\theta$ " respectively and the relative price $p$ be defined as $P_{A} / P_{M}$ (also known as agricultural terms-of-trade). Let the overall price index be given by $P=P_{A}^{\theta} P_{M}^{1-\theta}$. Using this, Equations (1) and (2) can be rewritten as,

$$
\begin{gathered}
\theta \equiv\left(P_{A} D_{A}\right) / P Y=\alpha+\left[(1-\alpha)\left(A_{0} / Y\right) p^{1-\theta}\right] \\
(1-\theta) \equiv\left(P_{M} D_{M}\right) / P Y=(1-\alpha)-\left[(1-\alpha)\left(A_{0} / Y\right) p^{1-\theta}\right]
\end{gathered}
$$

Note that, here " $Y$ " and " $p$ " are given exogenously to the utility maximising agent. However, at an aggregate level they are "equilibrium" variables, i.e., they come from demand-supply balance in the aggregate. The growth in " $Y$ " is a weighted average growth rate of the manufacturing and agricultural sectors. A change in the " $p$ " must be due a change in the demand-supply balance in relative terms. In other words, the observed " $Y$ " and " $p$ " are equilibrium values that come from the demand-supply balance at a point in time. The underlying demand curves are derived from the utility maximisation exercise with " $Y$ " and " $p$ " as "given". The focus here is on the demand side imbalances, without an explicit modelling of the supply side, with an underlying assumption that no imbalance is occurring from the supply side. Therefore, the model that follows is a "partial" equilibrium model.

From Equations (3) and (4), with $A_{0}=0$, expenditures shares are constant. So, unlike the Cobb-Douglas case, $\theta$ here is not a constant. As $Y$ increases, $\theta$ decreases and asymptotically approaches $\alpha$ from above. On the other hand, the expenditure share on " $\mathrm{M}$ " $(=1-\theta)$ increases and asymptotically approaches $(1-\alpha)$ from below. These are pure income effects, at constant prices. As a result, $\theta /(1-\theta)$ ratio will continuously decrease towards the long-run value $\alpha /(1-\alpha)$. This is exactly what happens to demand composition during structural change. Figure 1 captures such changes in expenditure shares with pure income effect. Here $\theta$ and $(1-\theta)$ can be treated as the short-run expenditure shares and $\alpha$ and $(1-\alpha)$ can be treated as long-run expenditure shares. We have assumed $(1-\alpha)>\alpha$ as typically in the long run, the expenditure share of manufacturing sector is more than that of the agricultural sector.

How does a change in the relative price of agri-sector affect the behaviour of expenditure shares over time? Note the following effects on the demand.

Income effect: demand for " $\mathrm{A}$ " is income inelastic, and that for " $\mathrm{M}$ " is income elastic.

Price effect: at the same level of $Y$, expenditure shares depend on the relative price $p$.

So, the expenditure shares depend on two variables, $p$ and $Y$ and therefore on the time-behaviour of $\left(A_{0} / Y\right) p^{1-\theta}$. Let $\beta=\left(A_{0} / Y\right) p^{1-\theta}$, so that 


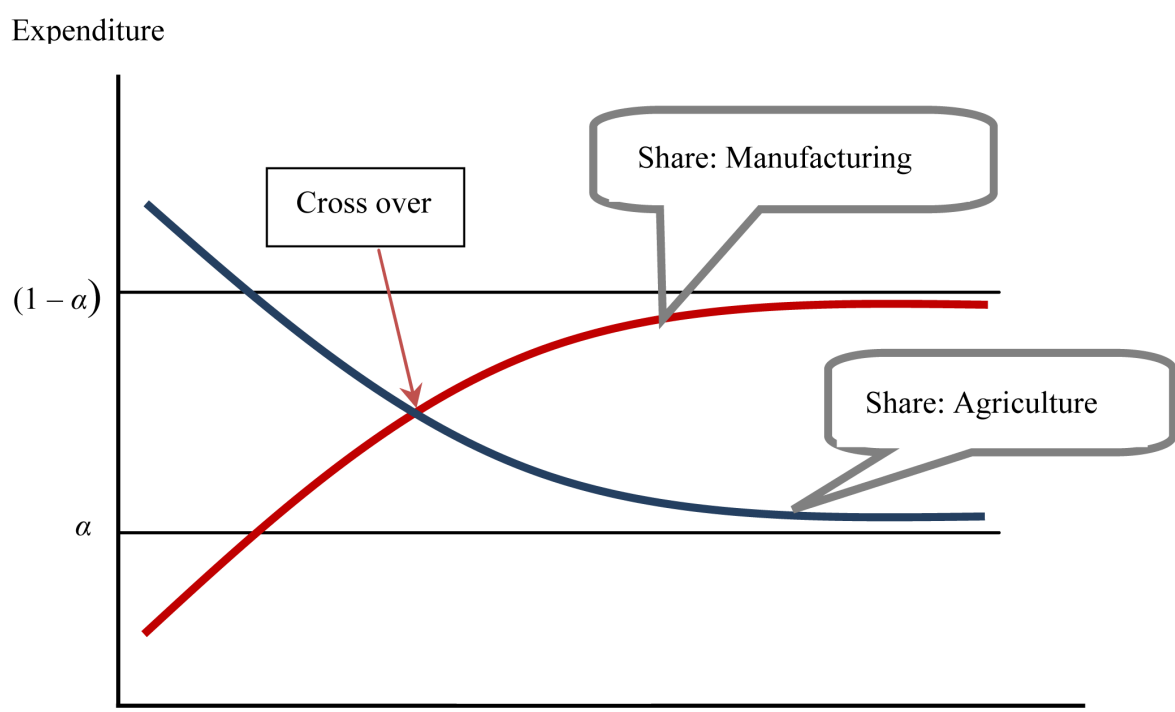

Time

Figure 1. Structural change with (only) income effect.

$$
\frac{\dot{\beta}}{\beta}=(1-\theta) \frac{\dot{p}}{p}-\frac{\dot{Y}}{Y}
$$

where an over dot implies the time rate of change.

Since $\theta<1$, the sufficient condition for $\beta$ to decrease is given by,

$$
\frac{\dot{p}}{p}>\frac{\dot{Y}}{Y}
$$

The following comments are immediate:

1) If the manufacturing share weighted proportionate increase in relative price equals the GDP growth rate (i.e. when the RHS of Equation (5) vanishes), expenditures shares remain constant. Developing economies usually begin with higher share of agriculture, and therefore would remain agrarian if this condition is satisfied.

2) The rate of decrease in $\beta$ is maximum when $p$ does not change, but when only GDP increases. Structural change will be most rapid in that case.

3) Higher the value of $\frac{\dot{p}}{p}$, the lower is the rate of decrease in $\beta$. Therefore, when $\frac{\dot{p}}{p}>0$ but $\frac{\dot{p}}{p}<\frac{\dot{Y}}{Y}$, the rate of changes in the expenditure shares would slow down compared to the case when only $Y$ increases, leading to what may be termed as "slow" structural change. This is an outcome of both the income and price effects. Note that, it is the unfavourable price effect that slows down the structural change.

What is the trend in $p$ in India? Chart 3 shows the trend in relative price during 1971-2014. Relative price is calculated by dividing Wholesale Price Index (base 2004-2005) of food articles by that of manufactured products. It shows a rising trend since 1980, with the trend becoming sharper since 1990. Similar observation has been noted by Rajan [10] and Krishnaswamy and Rajakumar [11].

Now the average growth rate in real GDP during 1994-2014 in India is 6.8 percent. The corresponding figure for $p$ stands at 2.68 percent, so we have $\frac{\dot{p}}{p}<\frac{\dot{Y}}{Y}$.

This meets the sufficient condition noted above, implying that structural change would slow down. Therefore, delayed "cross over" from the agriculture to manufacturing from the expenditure side may be attributed to the secular rise in the relative price of agriculture in India. Figure 2 captures such delayed structural change that incorporates both the income and relative price effects.

What policy lesson could one possibly draw from the analyses? It is this: to enable rapid structural transfor- 


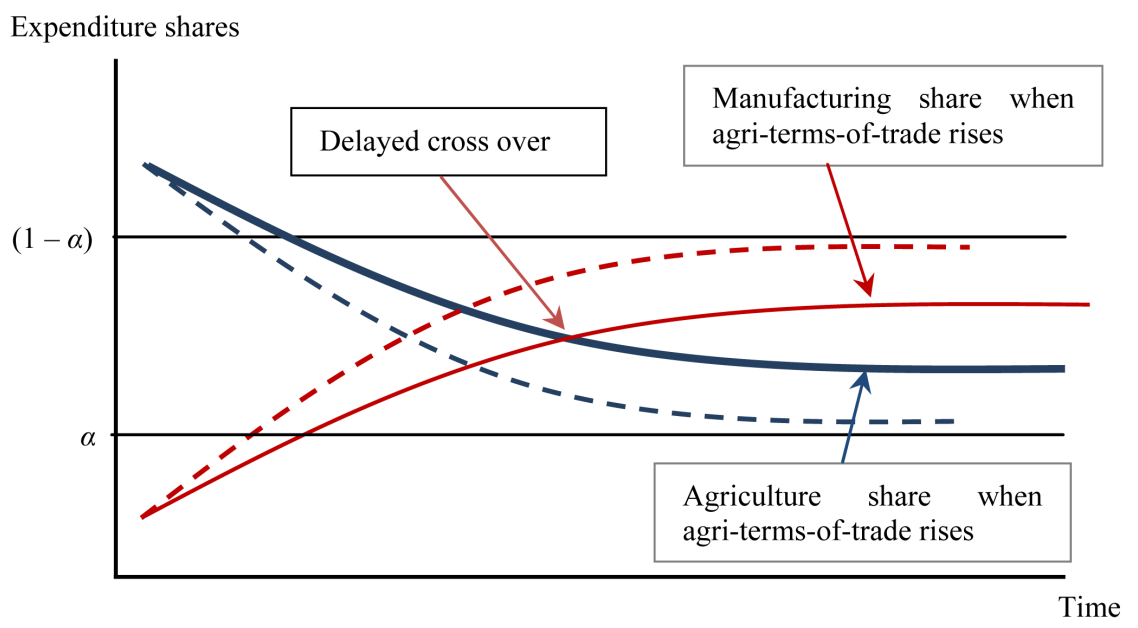

Figure 2. Delayed structural change with income and price effects.

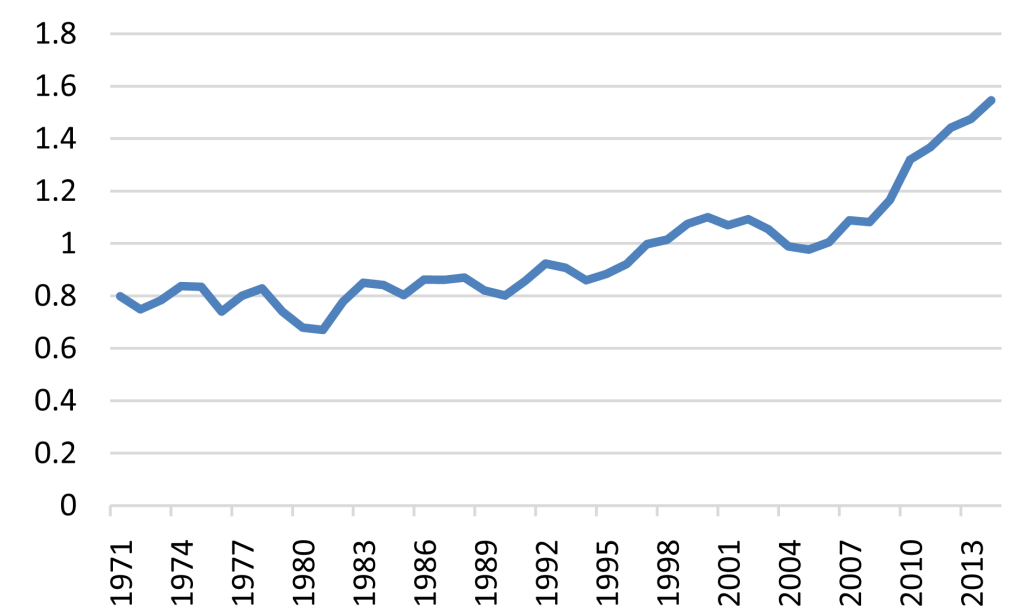

Chart 3. Trend in the relative price of food in India (1971-2014). Source: Author's calculation from EPWRF time series database.

mation, food prices need to be managed so that terms of trade does not turn against the manufacturing sector. Such policy lesson, however, is well known since the works of Lewis [12] and Kalecki [13] that try to capture the so called "structural" features of developing economies. In Lewis, rapid development of the urban/modern sector is dependent on the possibility of getting surplus labour from the backward sector at a constant real wage rate. Such possibility exists till the food prices are not rising, otherwise the "wage barrier" slows down transformation. Kalecki identifies issues related to financing of investment in the short run and possible effects on inflation due to shortages in supplies of essential commodities like food. It seems from the rising trend in the relative price of agricultural goods that the problems highlighted by Lewis and Kalecki still persist in countries like India.

\section{Pure and Relative Price Inflation}

What is the relation between relative price change and overall inflation? From price index, $P=P_{A}^{\theta} P_{M}^{1-\theta}$, overall inflation is given by,

$$
\pi=\theta \times \pi_{A}+(1-\theta) \times \pi_{M}
$$

where $\pi$ is inflation and is given by $\frac{\dot{p}}{p}$, and $\pi_{A}=\frac{\dot{p}_{A}}{p_{A}}, \pi_{M}=\frac{\dot{p}_{M}}{p_{M}}$. 
First consider the case when both $\pi_{A}$ and $\pi_{M}$ are constant; such constancy may be treated as a long-run trend (but long-run trend need not necessarily be time-constant). We can write from Equation (7), $\Delta \pi=\left(\pi_{A}-\pi_{M}\right) \Delta \theta$, and $\Delta \theta<0$ ( $\Delta$ is a change in the variable) because of structural change. If $\pi_{A}=\pi_{M}, \Delta \pi=0$, i.e., inflation will be constant without a change in the relative price. This is the case of pure inflation. Next consider the case when $\pi_{A}>\pi_{M}$ (with constant $\pi_{A}$ and $\pi_{M}$ ), implying $\Delta \pi<0$, i.e., inflation will decrease over time and will stabilise at $\pi=\alpha \pi_{A}+(1-\alpha) \pi_{M}$ (from above) in the long run. Similarly if $\pi_{M}>\pi_{A}, \Delta \pi>0$, i.e., inflation will increase over time and will stabilise at the same value (from below). Here variable inflation is an outcome of changes in relative price. Since, $p$ is rising in India and therefore $\left(\pi_{A} / \pi_{M}\right)>0$, foregoing analysis suggests that overall price level would increase at a decreasing rate.

Another source of variability comes from the variability (non-constancy) in $\pi_{A}$ and $\pi_{M}$, i.e., variability in sectoral inflation rates driven by seasonal factors or exogenous shocks like agricultural supply shock and oil price shock. These are deviations from the long-run trend. It would be an interesting exercise to see how much of overall inflation in India is due to pure inflation (when sectoral inflations are constant and equal), how much is due to relative price changes (when the trend in sectoral inflations are constant but unequal) and finally, how much is due to changes in sectoral inflation rates (when sectoral inflations are variable over trend and unequal); see Rather et al. [14] in this connection.

\section{Conclusion}

By looking at the expenditure side of economy in a partial equilibrium model, this paper has argued that unfavourable price effect has been slowing down the structural change in India. The relative price of agricultural goods has been rising in India since 1980. Such secular trend in the relative price can have significant effect on the pace of structural change as structural change is associated with income and price effects. While rapid growth in national income accelerates structural change, increase in the relative price of income and price inelastic goods slows it down. One must note that the paper does not incorporate the supply side, i.e., it does not employ a "general equilibrium" model. That requires modelling of the supply side as well.

\section{References}

[1] Kuznets, S. (1973) Modern Economic Growth: Findings and Reflections. American Economic Review, 63, $247-258$.

[2] Varma, R. (2012) Structural Transformation and Jobless Growth in the Indian Economy. In: Chetan, G., Ed., The Oxford Handbook of the Indian Economy, Oxford University Press, New York. http://dx.doi.org/10.1093/oxfordhb/9780199734580.013.0010

[3] Kongsamut, P., Rebelo, S. and Xie, D. (2001) Beyond Balanced Growth. Review of Economic Studies, 68, 869-882. http://dx.doi.org/10.1111/1467-937X.00193

[4] World Economic and Social Survey (2006) Diverging Growth and Development. United Nations.

[5] Memedovic, O. (2009) Structural Change in the World Economy: Main Features and Trends. United Nations Industrial Development Organization, Working Paper No. 24.

[6] Acemoglu, D. (2009) Introduction to Modern Economic Growth. Princeton University Press, New Jersey.

[7] Boppart, T. (2014) Structural Change and the Kaldor Facts in a Growth Model with Relative Price Effects and NonGorman Preferences. Econometrica, 82, 2167-2196. http://dx.doi.org/10.3982/ECTA11354

[8] Binswanger-Mkhize, H.P. (2013) The Stunted Structural Transformation of the Indian Economy. Economic and Political Weekly, 48, 5-13.

[9] Economic and Political Weekly Research Foundation: India Time Series. http://www.epwrfits.in

[10] Rajan, R. (2014) Fighting Inflation. RBI Monthly Bulletin, March, 11-20.

[11] Krishnaswamy, R. and Rajakumar, D. (2015) Recent Trends in Inter-Sectoral Terms of Trade. Economic and Political Weekly, 50, 82-84.

[12] Lewis, W.A. (1954) Economic Development with Unlimited Supplies of Labour. The Manchester School, 22, $139-191$. http://dx.doi.org/10.1111/j.1467-9957.1954.tb00021.x

[13] Kalecki, M. (1955) The Problem of Financing of Economic Development. Indian Economic Review, 2, 1-22.

[14] Rather, S.R., Durai, S.R.S. and Ramachandran, M. (2014) Inflation and Relative Price Variability: Evidence for India. Journal of Asian Economics, 30, 32-41. http://dx.doi.org/10.1016/j.asieco.2013.12.002 